CLINICAL STUDY

\title{
Expression profile of apoptosis-related genes in childhood adrenocortical tumors: low level of expression of $B C L 2$ and TNF genes suggests a poor prognosis
}

Cecília Fernandes Lorea ${ }^{1}$, Daniel Antunes Moreno ${ }^{2}$, Kleiton Silva Borges ${ }^{2}$, Carlos Eduardo Martinelli Jr ${ }^{1}$, Sonir Roberto Rauber Antonini ${ }^{1}$, Margaret de Castro $^{3}$, Silvio Tucci Jr ${ }^{4}$, Luciano Neder ${ }^{5}$, Leandra Naira Zambelli Ramalho ${ }^{5}$, Izilda Cardinalli ${ }^{6}$, Ana Luiza Seidinger ${ }^{6}$, Maria José Mastellaro ${ }^{6}$, José Andres Yunes ${ }^{6}$, Silvia Regina Brandalise ${ }^{6}$, Luiz Gonzaga Tone ${ }^{1}$ and Carlos Alberto Scrideli ${ }^{1}$

Departments of ${ }^{1}$ Pediatrics, ${ }^{2}$ Genetics, ${ }^{3}$ Internal Medicine, ${ }^{4}$ Surgery and ${ }^{5}$ Pathology, Faculty of Medicine of Ribeirão Preto, University of São Paulo, 14049-900 Ribeirão Preto, São Paulo, Brazil and ${ }^{6}$ Centro Infantil Boldrini/UNICAMP, 13083-210 Campinas, São Paulo, Brazil

(Correspondence should be addressed to C A Scrideli who is now at Department of Pediatrics, Faculty of Medicine of Ribeirão Preto, University of São Paulo; Email: scrideli@fmrp.usp.br)

\begin{abstract}
Background: Impaired apoptosis has been implicated in the development of childhood adrenocortical tumors (ACT), although the expression of apoptosis-related gene expression in such tumors has not been reported.

Methods: The mRNA expression levels of the genes CASP3, CASP8, CASP9, FAS, TNF, NFKB, and BCL2 were analyzed by quantitative real-time PCR in consecutive tumor samples obtained at diagnosis from 60 children with a diagnosis of ACT and in 11 non-neoplastic adrenal samples. BCL2 and TNF protein expression was analyzed by immunohistochemistry.

Results: A significant association was observed between tumor size $\geq 100 \mathrm{~g}$ and lower expression levels of the BCL2 $(P=0.03)$ and TNF $(P=0.05)$ genes; between stage IV and lower expression levels of CASP3 $(P=0.008)$, CASP9 $(P=0.02), B C L 2(P=0.002)$, TNF $(P=0.05)$, and NFKB $(P=0.03)$; Weiss score $\geq 3$ and lower expression of TNF $(P=0.01)$; unfavorable event and higher expression values of CASP9 $(P=0.01)$ and lower values of TNF $(P=0.02)$; and death and lower expression of BCL2 $(P=0.04)$. Underexpression of TNF was associated with lower event-free survival in uni- and multivariate analyses $(P<0.01)$. Similar results were observed when patients with Weiss score $<3$ were excluded.

Conclusion: This study supports the participation of apoptosis-related genes in the biology and prognosis of childhood ACT and suggests the complex role of these genes in the pathogenesis of this tumor.
\end{abstract}

European Journal of Endocrinology 167 199-208

\section{Introduction}

Adrenocortical tumors (ACT) are rare childhood neoplasias with a very low incidence in children, corresponding to only $0.2 \%$ of pediatric cancers $(1,2$, 3). However, in Southern Brazil, an inherited germline TP53 mutation ( $p . R 337 \mathrm{H})$ greatly increases the predisposition to the development of childhood ACT, estimated to be 10-15 times higher than the worldwide incidence, and this mutation has been found in over $80 \%$ of Brazilian patients with childhood ACT $(4,5,6)$.

In children, ACT appear more often during the first 5 years of life and normally cause endocrine disorders, the most common being virilization alone or in combination with hypercortisolism $(2,3)$. The differentiation of malignant and benign forms of childhood ACT is difficult and, to date, there are no histological or molecular markers that can reliably distinguish between them $(1,2)$.

It has been speculated that malignant transformation could originate from abnormal persistence and/or defective apoptosis of the fetal adrenal cortex $(7,8,9)$, and although some studies have been conducted on cell lines (10), the role of apoptosis-related genes in childhood ACT has not been evaluated.

The study of apoptosis-related genes in ACT could be important not only to promote new insights into the biology of ACT but also to determine potential prognostic and therapeutic markers. On this basis, the aim of this study was to evaluate the gene expression profile of key genes related to apoptosis (CASP3, CASP8, CASP9, FAS, BCL2, TNF, and NFKB) by 
quantitative real-time PCR in consecutive newly diagnosed children and adolescents with ACT and to analyze its association with clinical/biological characteristics and prognosis.

\section{Materials and methods}

\section{Subjects}

Sixty consecutive pediatric patients with ACT diagnosed between October 1991 and July 2009 at two reference centers in Southeast Brazil (Faculty of Medicine of Ribeirao Preto, University of Sao Paulo, and Centro Infantil Boldrini, Campinas) were enrolled in the study. All patients underwent appropriate clinical and hormonal investigation. Following the biochemical tests, abdominal computed tomography (CT) and/or magnetic resonance imaging (MRI) were performed. Additionally, chest CT and bone scintigraphy were performed for the detection of metastases. Disease stage was classified according to the Sandrini classification proposed for childhood ACT (11) and the histological diagnosis was based on the criteria of Weiss (12). Eleven non-neoplastic adrenal cortex samples from children aged 2-6 years were used as control. Samples were obtained during nephrectomy due to Wilms' tumor before any chemotherapy. Adrenal invasion was excluded by conventional microscopy. The study was approved by the local ethics committees (protocol numbers 9374/2003 and 8380/2010), and a signed statement of informed consent was obtained from the parents of the pediatric patients and control subjects.

We evaluated 46 girls and 14 boys with a mean age at diagnosis of 40.5 months (range: 5-187 months). Hormone-secreting tumors were diagnosed in 57 patients: 37 were androgen-secreting tumors, 18 mixed cortisol- and androgen-secreting tumors, and two cortisol-secreting tumors. Two patients had non-secreting tumors and one had no available data. Thirty-five patients were classified as stage I, ten as stage II, eight as stage III, and seven as stage IV according to Sandrini's classification. The TP53p.R337H mutation was evaluated by direct DNA sequencing and was found in 52/60 (86.6\%) patients with ACT. Forty-six patients $(76.6 \%)$ had Weiss classification scores $\geq 3,13$ had scores $<3$, and one had an undetermined score. Clinical and pathological features including gender, age, histology according to Weiss classification, clinical presentation, tumor size, stage, TP53-p.R337H mutation, and follow-up status are described in Supplementary Table 1, see section on supplementary data given at the end of this article.

Analysis of overall survival (OS) revealed a higher 5-year OS for patients younger than 4 years (90.6 vs $53.8 \% ; P=0.004)$, with tumor size $<100 \mathrm{~g}(97.2$ vs 48.5, $P<0.0001)$ and $<200 \mathrm{~cm}^{3}(92.5$ vs 47.6 ,
$P<0.0001)$, which was marginally significant compared with patients classified as Weiss criteria $<3$ (100 vs $74.8 \%, P=0.05$ ). When we analyzed survival according to Sandrini's classification, the 5-year OS was $96.9,68.6,68.6$, and $33.3 \%$ for stages I, II, III, and IV respectively $(P=0.001)$. OS did not differ regarding TP53 R337H status $(P=0.16)$. Follow-up ranged from 8 to 168 months (median: 68.3 months) and three patients were lost to follow-up. These data are shown in Table 1.

The characteristics of our sample regarding clinical data such as age, sex, stage, clinical symptoms, survival, and prognostic factors were similar to those described by the International Pediatric Adrenocortical Tumor Registry (IPACTR) (1) and the frequency of the TP53-p.R337H mutation was also similar to that observed in other Brazilian childhood ACT series $(4,5,6)$.

\section{mRNA quantification by real-time PCR (RT-PCR)}

The frozen tumor tissue and control adrenal cortex samples were microdissected by an experienced pathologist for exclusion of tissue areas presenting necrosis or not matching ACT diagnostic before RNA extraction. For tumor microdissection, tumor samples were placed on a cooled platform and immediately positioned on the cutting base of the cryostat under Tissue Tek (Fisher Scientific, Pittsburg, PA, USA). After rapid freezing in liquid nitrogen, the sample was cut and immediately

Table 1 Five-year event-free survival (EFS) and overall survival (OS) according to clinical features and Sandrini's classification.

\begin{tabular}{|c|c|c|c|c|}
\hline Genes & $\begin{array}{l}\text { 5-year } \\
\text { EFS }\end{array}$ & $P$ & $\begin{array}{l}\text { 5-year } \\
\text { OS }\end{array}$ & $\boldsymbol{P}$ \\
\hline \multicolumn{5}{|l|}{ Age } \\
\hline$<4$ years $(n: 46)$ & $81.2 \pm 6.0$ & $0.002^{*}$ & $90.6 \pm 4.5$ & $0.004^{\star}$ \\
\hline$\geq 4$ years $(n: 14)$ & $36.9 \pm 13.8$ & & $53.8 \pm 13.8$ & \\
\hline \multicolumn{5}{|l|}{ Tumor size } \\
\hline$<100 \mathrm{~g}(n: 40)$ & $88.3 \pm 5.5$ & $<0.001^{\star}$ & $97.2 \pm 2.7$ & $<0.001^{*}$ \\
\hline$\geq 100 \mathrm{~g}(n: 20)$ & $36.7 \pm 11.6$ & & $48.5 \pm 12.1$ & \\
\hline$<200 \mathrm{~cm}^{3}(n: 44)$ & $84.4 \pm 5.9$ & $<0.001^{\star}$ & $92.5 \pm 4.2$ & $<0.001^{\star}$ \\
\hline$\geq 200 \mathrm{~cm}^{3}(n: 16)$ & $35.2 \pm 12.4$ & & $47.6 \pm 13.8$ & \\
\hline \multicolumn{5}{|l|}{ Pathology ${ }^{a}$} \\
\hline $\begin{array}{l}\text { Weiss criteria }<3 \\
(n: 13)\end{array}$ & $100.0 \pm 0.0$ & $0.01^{*}$ & $100.0 \pm 0.0$ & $0.05^{\star}$ \\
\hline $\begin{array}{l}\text { Weiss criteria } \geq 3 \\
\quad(n: 46)\end{array}$ & $60.7 \pm 7.9$ & & $74.8 \pm 7.0$ & \\
\hline \multicolumn{5}{|l|}{ TP53 R337H status } \\
\hline Negative ( $n: 8)$ & $85.7 \pm 13.2$ & 0.24 & $100.0 \pm 0.0$ & 0.16 \\
\hline Positive (n: 52) & $68.0 \pm 6.9$ & & $78.1 \pm 6.1$ & \\
\hline \multicolumn{5}{|l|}{$\begin{array}{l}\text { Classification } \\
\text { (Sandrini) }\end{array}$} \\
\hline Stage $1(n: 35)$ & $86.8 \pm 6.2$ & $0.003^{\star}$ & $96.9 \pm 3.1$ & $0.001^{*}$ \\
\hline Stage II (n: 10) & $54.9 \pm 17.2$ & & $68.6 \pm 15.1$ & \\
\hline Stage III (n: 8) & $62.5 \pm 17.1$ & & $68.6 \pm 18.6$ & \\
\hline Stage IV (n: 7) & $28.6 \pm 17.1$ & & $33.3 \pm 19.2$ & \\
\hline
\end{tabular}

*Statistically significant $(P \leq 0.05)$ values are in bold.

${ }^{\mathrm{a} O n e}$ patient with an indeterminate score. 
captured on a coverslip, stained with hematoxylin and eosin, and evaluated by image apposition. The area of interest in the original cryopreserved tumor block was then trimmed, and the microdissected sample was transferred to a previously identified tube, which was immediately placed under dry ice. Total RNA was extracted from tumor and control tissue samples using TRIzol Reagent (Invitrogen) according to the manufacturer's protocol. The RNA samples were evaluated by $1.2 \%$ agarose gel electrophoresis and quantified by spectrophotometry. cDNA synthesis was performed with the High-Capacity cDNA Reverse Transcription kit (Applied Biosystems, Foster City, CA, USA) and MultiScribe enzyme using $500 \mathrm{ng}$ RNA in a $25 \mu \mathrm{l}$ reaction.

The relative mRNA expression levels of the genes analyzed were quantified using real-time PCR analysis with the ABI PRISM 7700 Sequence Detection System (Applied Biosystems, Inc.). The specific sequences were amplified with the SYBR Green PCR Master Mix (Applied Biosystems, Inc.). All samples were analyzed in triplicate using GUSB as the reference gene. Each run was completed with a melting curve analysis to confirm the specificity of amplification and the lack of primer dimers. The efficiency $(E)$ of each primer set was tested on dilutions of control cDNA samples and ranged from 1.9 to 2.1 . The $2^{-\Delta \Delta C_{\mathrm{t}}}$ equation was applied to calculate the relative gene expression (13). The same sample of non-neoplastic adrenal tissue was used as calibrator in all reactions. The median gene expression values of all non-neoplastic adrenal tissues were used as reference and defined as 1 . The primers for the CASP3 (sense (S): GGTATCCATGGAGAACACTGAA, antisense (AS): GAGTCCATTGATTCGCTTCC), CASP8 (S: TTGCAAGAGGAAATCTCCAAA, AS: TCCAGCAGGTCCATGTCATCATC), CASP9 (S: CTGTTCAGGCCCCATATGAT, AS: CTGGCCTGTGTCCTCTAAGC), FAS (S: GCATCTGGACCCTCCTACCT, AS: CCAATCCCTTGGAGTTGATG), BCL2 (S: ATGTGTGTGGAGAGCGTCAA, AS: GCCGTACAGTTCCACAAAGG), NFKB (p65) (S: CCACGACTTGTAGGAAAGG, AS: CTGGATGCGCTGACTGATAG), TNF (S: CTCTTCTGCCTGCTGCACTT, AS: GCCAGAGGGCTGATTAGAGA), and GUSB (S: GAAAATATGTGGTTGG
AGAGCTCATT, AS: CCGAGTGAAGATCCCCTTTTTA) genes were designed in different exons using the Primer 3 v.04 program (http://frodo.wi.mit.edu/primer3/) and synthesized by Invitrogen.

\section{Immunohistochemical analysis}

Immunohistochemical (IHC) studies were performed on a subset of 28 tumor tissue samples. Briefly, $3 \mu \mathrm{m}$-thick sections cut from paraffin blocks containing representative tumor samples were mounted on poly-L-lysinecoated slides, deparaffinized, rehydrated, immersed in $10 \mathrm{mmol} / \mathrm{l}$ citrate buffer, $\mathrm{pH}$ 6.0, and submitted to heatinduced epitope retrieval using a vapor lock for $45 \mathrm{~min}$. The slides were rinsed with PBS and immersed in 3\% hydrogen peroxide for $20 \mathrm{~min}$ to block endogenous peroxidase. Non-specific protein binding was blocked with normal serum (Vectastain Elite ABC Kit, Universal, Vector Laboratories, Inc., Burlingame, CA, USA) for $30 \mathrm{~min}$. The sections were then incubated with monoclonal primary antibodies specific for BCL2 (dilution 1:100; Dako, Carpenteria, CA, USA or Millipore, Temecula, CA, USA) and TNF (dilution 1:100; Millipore) for $2 \mathrm{~h}$ at room temperature $\left(25^{\circ} \mathrm{C}\right)$ in a humid chamber. Following washes in PBS, a biotinylated pan-specific universal secondary antibody (Vectastain Elite ABC Kit, Universal, Vector Laboratories, Inc.) was applied for $30 \mathrm{~min}$. Next, the slides were incubated with the avidin-biotin-peroxidase complex (Vectastain Elite ABC Kit, Universal, Vector Laboratories, Inc.) for $30 \mathrm{~min}$ and developed with the DAB Peroxidase Substrate Kit, 3,3'-diaminobenzidine + Nyquil (Vector Laboratories, Inc.) for $5 \mathrm{~min}$. The slides were counterstained with Harris hematoxylin, dehydrated, and mounted with Permount (Biomeda, Foster City, CA, USA). Normal skin was used as the positive control for all antibodies. As negative controls, all specimens were incubated with an isotope-matched control antibody under identical conditions. Each sample was defined on the basis of percentage of stained cells: negative $(<1 \%)$, weak (1-10\%), moderate (10-50\%), and strong $(>50 \%)$.

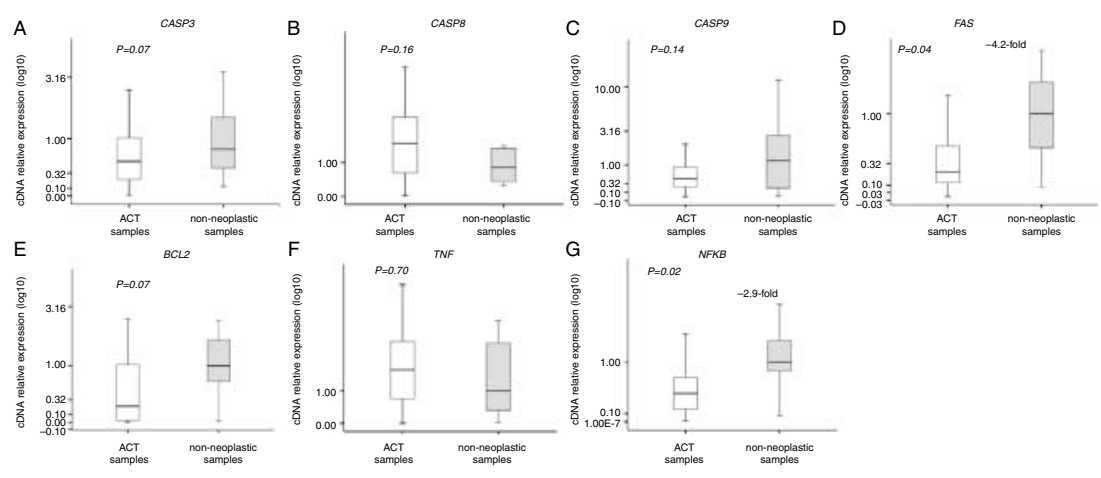

Figure 1 Relative mRNA expression of genes CASP3 (A), CASP8 (B), CASP9 (C), $F A S(\mathrm{D}), B C L 2(\mathrm{E}), T N F(\mathrm{~F})$, and $N F K B(\mathrm{G})$ in childhood ACT and childhood nonneoplastic adrenal cortex. The lines correspond to the median value of expression. Results are presented as $\log 10$ scale and differences that were significant by the Mann-Whitney $U$ test are expressed as fold-change in relation to the expression observed in normal adrenal glands. 


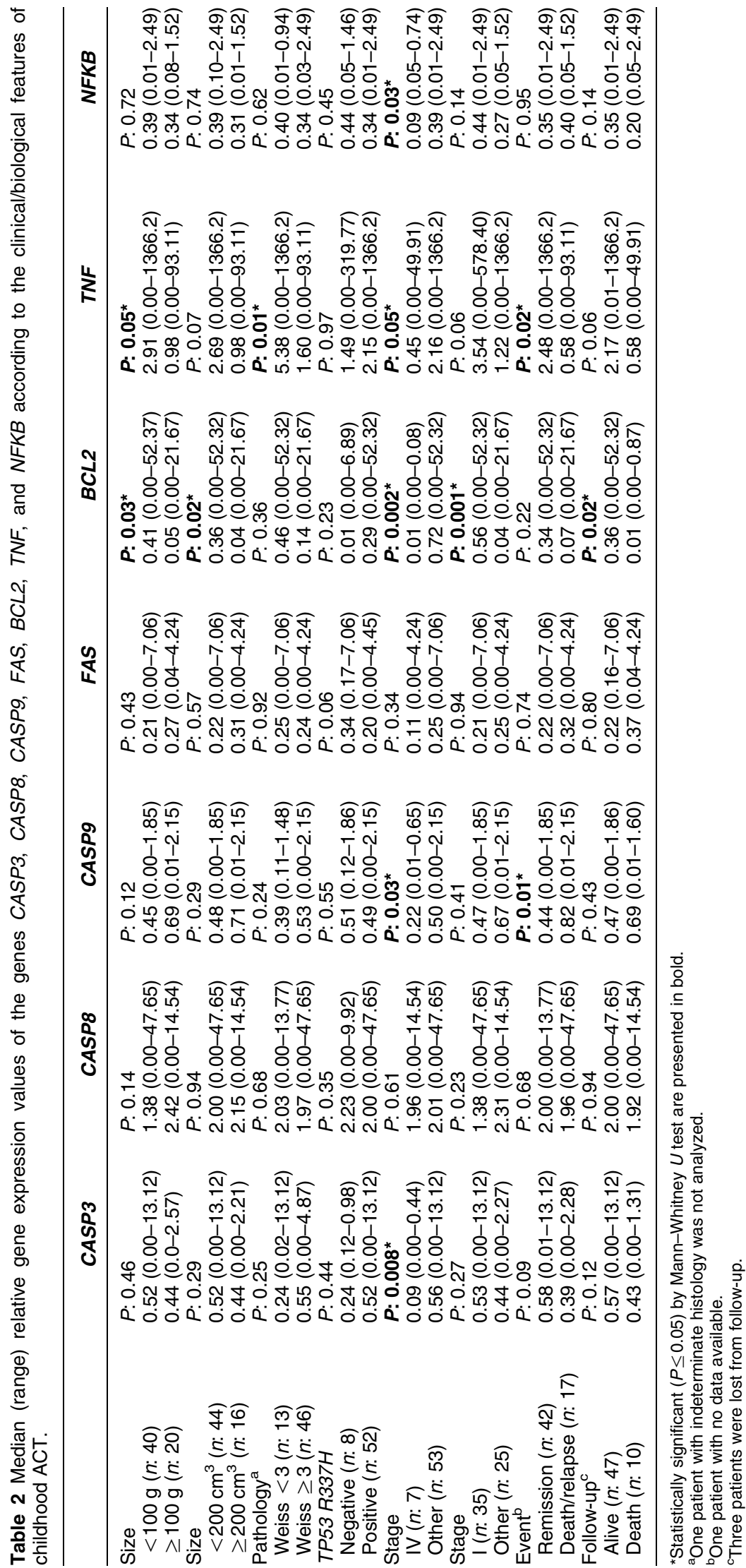




\section{Statistical analysis}

The association of the variables age ( $<$ vs $\geq 4$ years), tumor weight $(<$ vs $\geq 100 \mathrm{~g})$, tumor size $(<$ vs $\geq 200 \mathrm{~cm}^{3}$ ), TP53-p.R377H mutation (positive vs negative), pathology (Weiss criteria $<3$ vs Weiss criteria $\geq 3$ ), disease stage according to Sandrini's classification at diagnosis (stage IV vs other and stage I vs other), event-free survival (EFS) (death/relapse vs complete remission), OS (death vs alive) and the expression levels of each gene analyzed was determined by the MannWhitney $U$ test. Survival analysis was carried out based on Kaplan-Meier curves, using -2-fold of the gene expression observed in the control samples as cutoff points for EFS, with relapse and/or death due to any cause considered as unfavorable events, and for OS, with death considered as an unfavorable event. Curves for different groups were compared by the log-rank test. The Cox proportional regression model was used for multivariable analysis of prognostic factors and also to estimate the association between lower or higher -2-fold expression values and risk of an unfavorable event or death, with calculation of the hazard ratio and
95\% confidence interval. Three patients were lost to follow-up after relapse and were analyzed only for EFS and censored at the time of relapse. One patient had no information about the relapse date and was excluded from the EFS analysis. The correlation between the expression values of the genes studied was determined by the Spearman correlation coefficient. The level of significance was set at $P \leq 0.05$ in all analyses. Data were analyzed using the SPSS Graduate Pack 15.0 software (SPSS, Inc., Chicago, IL, USA).

\section{Results}

\section{Expression of apoptosis-related genes in ACT and non-neoplastic controls}

Compared with non-neoplastic adrenal samples, ACT presented significantly lower expression levels of genes FAS ( -4.2 -fold, $P=0.004)$ and NFKB ( -2.9 -fold, $P=0.02$ ) (Fig. 1). Patients classified as having carcinomas (Weiss score $\geq 3$ ) had significantly lower expression of genes FAS $(P=0.003)$, BCL2 $(P=0.03)$, and NFKB
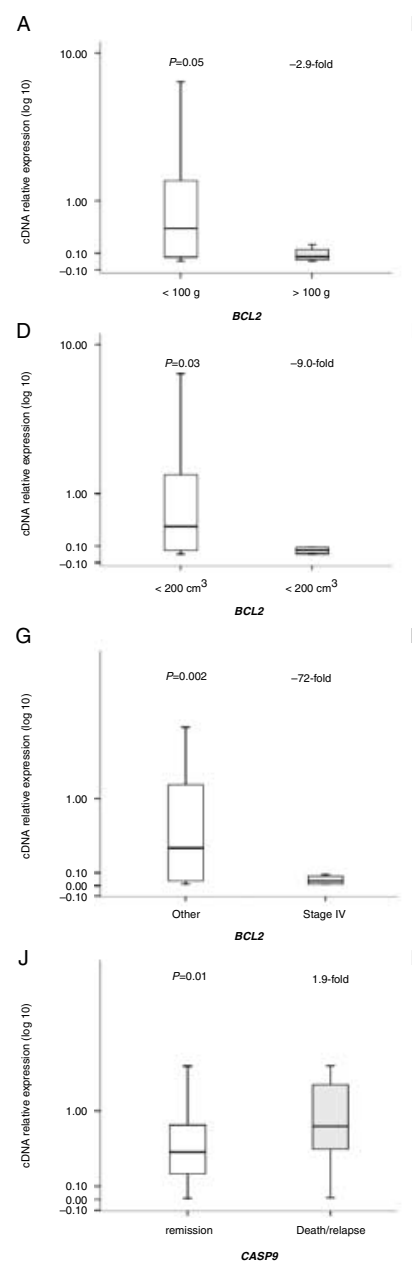

B
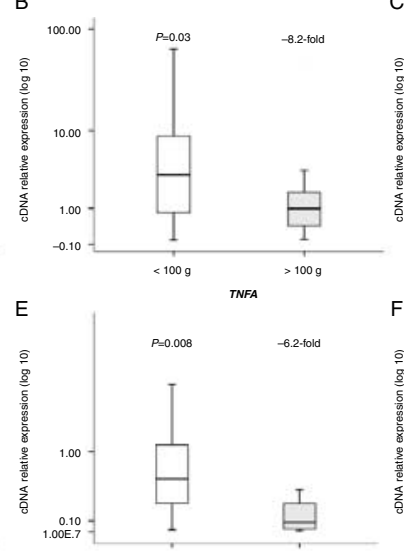

$\mathrm{H}$
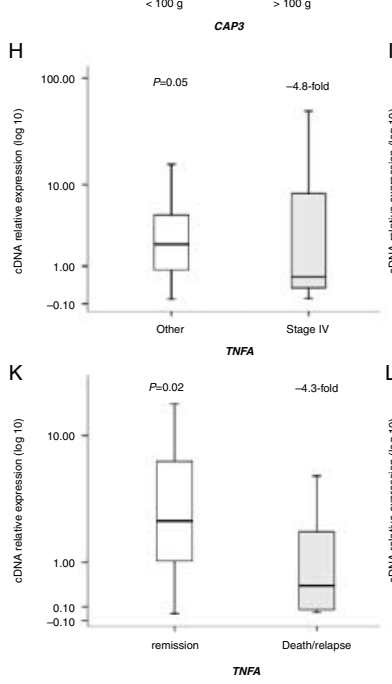

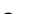
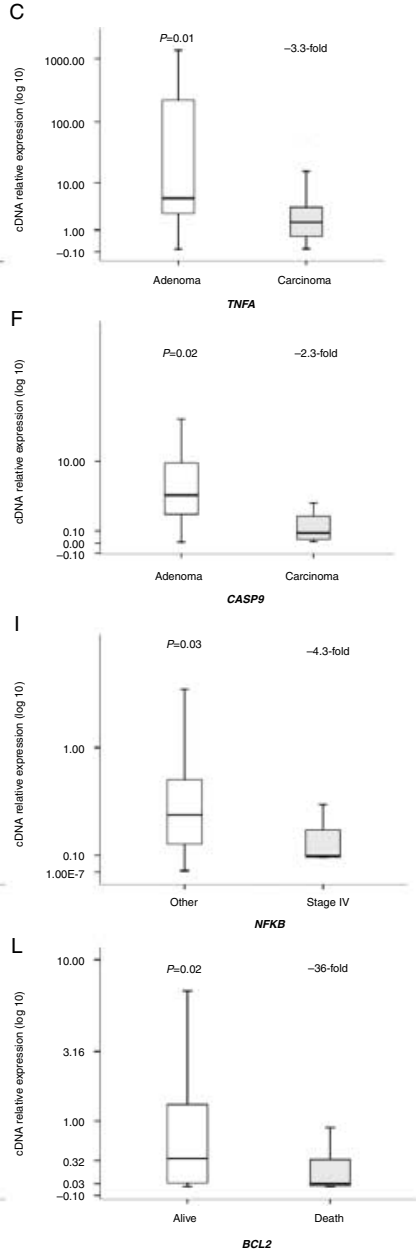

Figure 2 Relative mRNA expression of the genes analyzed in association with tumor size ( $<$ or $\geq 100 \mathrm{~g}$ ) with $B C L 2(\mathrm{~A})$ and TNF (B); Weiss score (adenoma or carcinoma) with $T N F(C)$ ; tumor size $\left(<\right.$ or $\left.\geq 200 \mathrm{~cm}^{3}\right)$ with $B C L 2$ (D); stage IV classification with CASP3 (E), CASP9 (F), BCL2 (G), $T N F(\mathrm{H})$, and NFKB (I); unfavorable event with CASP9 $(\mathrm{J})$ and $T N F(\mathrm{~K})$; and death with $B C L 2$ gene $(L)$ in the overall group childhood ACT. The lines correspond to the median value of expression. Results are presented in log10 scale and are expressed as fold-change. All differences were significant by the Mann-Whitney $U$ test. 

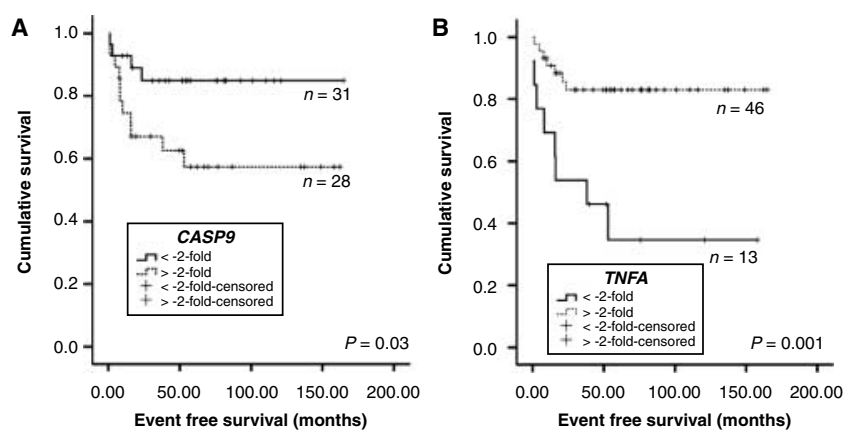

Figure 3 Kaplan-Meier plots of cumulative event-free survival (EFS) and cumulative incidence of events according to the relative gene expression below or -2-fold above the non-neoplastic adrenal samples for CASP9 (A) and TNF (B) in patients with adrenocortical tumors.

$(P=0.03)$ when compared with non-neoplastic adrenal samples and a lower expression of TNF $(P=0.01)$ when compared with patients with adenomas (Weiss score $<3$ ).

\section{Expression of apoptosis-related genes and clinical and biological characteristics}

A positive correlation was observed by the Spearman test between the FAS gene and genes CASP 3 (correlation coefficient $0.48, P<0.001$ ), CASP8 (correlation coefficient $0.30, P=0.01$ ), and CASP9 (correlation coefficient $0.32, P=0.007)$. A positive correlation was also observed between BCL2 and TNF (correlation coefficient $0.32, P=0.007$ ) and NFKB (correlation coefficient $0.49, P<0.001$ ), indicating a common and uniform activation of these two groups of genes, regardless of the heterogeneity of the clinical stage of the sample studied.

TNF underexpression was more pronounced in ACT with $\geq 100 \mathrm{~g}$, Weiss scores $\geq 3$, classified as stage IV, and presence of unfavorable event (relapse or death). $B C L 2$ underexpression was found in ACT with $\geq 100 \mathrm{~g}$, $\geq 200 \mathrm{~cm}^{3}$, stage IV, and in association with death event. Underexpression of CASP3, CASP9, and NFKB was also associated with stage IV classification. Overexpression of CASP9 was associated with unfavorable events. These data are shown in Table 2 and Fig. 2. It is interesting to point out that in our study, the mean BCL2 gene expression was significantly higher in patients with mitotic index $\leq 5 / 50$ HPF $(8.84$ vs $0.42, P=0.002$ ).

In order to analyze a possible correlation between the expression levels of apoptosis-related genes and 5-year EFS and OS, the patients were divided into two groups using -2-fold decreased expression values of nonneoplastic adrenal samples to define low expression.

Lower expression of the TNF gene was associated with a lower EFS ( 34.6 vs $83.0 \%, P=0.001$ ) and lower expression of CASP9 with a higher 5-year EFS (84.1 vs
$57.4 \%, P=0.03$ ) (Fig. 3). Low expression of TNF was also an independent unfavorable prognostic factor $(P=0.001)$ when analyzed in combination with age $(P=1.00)$ and tumor size $\geq 100 \mathrm{~g}(P=0.002)$. No significant differences were observed in EFS or OS for the other genes. When we analyzed only patients classified as having carcinomas, similar results were observed with several of the genes analyzed, showing a significant association with clinical and biological features, as illustrated in Fig. 4.

A lower 5-year EFS was observed for patients with low expression of the TNF gene $(24.2$ vs $76.6 \%$, $P=0.002)$ and CASP 3 (41.9 vs $78.8 \%, P=0.03)$ (Fig. 5). Multivariable analysis showed that TNF expression below -2 -fold was an independent unfavorable prognostic factor $(P=0.01)$ when analyzed in combination with age $\geq 4$ years $(P=0.97)$ and tumor size $\geq 100 \mathrm{~g}(P=0.04)$.

\section{Expression of BCL2 and TNF determined by IHC and survival}

The BCL2 and TNF protein expression was evaluated by IHC, and the results were similar to those observed by RQ-PCR. Of the 28 ACT samples analyzed for BCL2 protein, ten $(35.7 \%)$ presented strong cytoplasmic immunoreactivity ( $>50 \%$ of the cells), while immunoreactivity was moderate $(10-50 \%$ of the cells) in six $(21.4 \%)$ and negative or weak $(<10 \%)$ in $12(42.9 \%)$. In the group with strong/moderate immunoreactivity for BCL2 protein, the median relative mRNA expression detected by RQ-PCR was 0.375 , and in the group with expression of $<10 \%$, the median mRNA expression was 0.007. Regarding TNF, cytoplasmic immunoreactivity was strong in ten $(35.7 \%)$, moderate in four $(14.3 \%)$, and negative or weak $(<10 \%)$ in $14(50 \%)$. In the group with strong/moderate immunoreactivity for TNF protein, the median of relative mRNA expression detected by RQ-PCR was 1.896 , and in the group with expression $<10 \%$, the median mRNA expression was 0.056.

The 5-year EFS was higher in patients with strong/moderate BCL2 immunoreactivity (92.9 vs $33.3 \%, P=0.002)$, as also was the 5 -year OS (100 vs $54.5 \%, P=0.05)$. Regarding TNF, patients with strong/moderate immunoreactivity had a higher 5 -year EFS (83.3 vs $48.6 \%, P=0.10)$ as well as a higher 5-year OS $(100$ vs $66.7 \%, P=0.04)$. A representative BCL2 and TNF IHC staining is shown in Fig. 6.

\section{Discussion}

During the embryologic period, the fetal cortex corresponds to $85 \%$ of the adrenal cortex and disappears rapidly after birth due to a massive apoptosis process $(7,14,15)$. Similarities exist between normal 

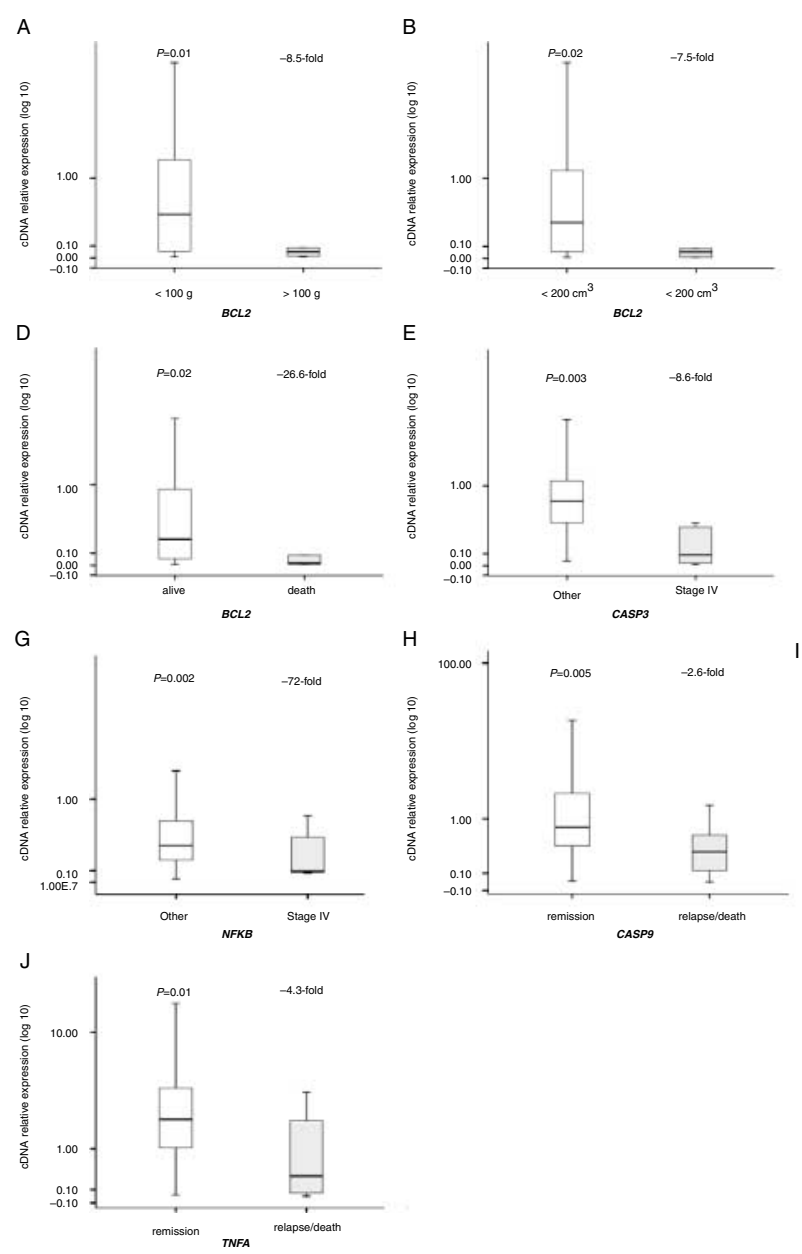

human fetal cortex and adrenal cancer, and it has been speculated that the malignant transformation may originate from abnormal persistence and/or defective apoptosis of this fetal adrenal cortex $(7,8,9)$. Alteration of the apoptotic pathway is a central mechanism of survival in cancer, and TP53 is an important key gene in the control of this pathway $(16,17)$. The study of apoptosis-related genes in a tumor so closely related to TP53 mutation could provide new insights into the understanding of ACT biology.

In our study, childhood non-neoplastic adrenal samples presented a significantly higher expression of FAS and NFKB and a trend to significant expression of the BCL2 and CASP3 genes when compared with childhood ACT samples, suggesting a different profile of apoptosis-related genes in normal and neoplastic adrenals. As non-neoplastic adrenal tissues obtained from nephrectomy for Wilms tumors could not reproduce exactly the normal counterpart of the ACT samples, these results should be viewed with caution.

Apoptosis-related gene expression in childhood ACT has been little studied until now. It is interesting to point out that in the only study using gene expression analysis in childhood ACT by microarray (15), which
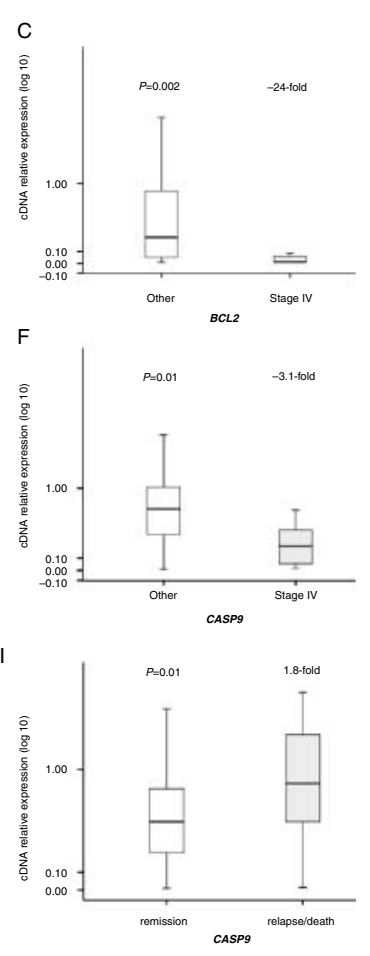

Figure 4 Relative mRNA expression of the genes analyzed in association with tumor size $(<$ or $\geq 100 \mathrm{~g})$ with $B C L 2$ (A); tumor size ( $<$ or $\geq 200 \mathrm{~cm}^{3}$ ) with $B C L 2$ (B); stage IV classification with $B C L 2(C)$; death with $B C L 2$ (D); stage IV classification with $C A S P 3(\mathrm{E})$, CASP9 $(\mathrm{F})$, and $N F K B(\mathrm{G})$; unfavorable event with $C A S P 3(\mathrm{H}), C A S P 9(\mathrm{I})$, and $T N F(\mathrm{~J})$ in the group of childhood adrenocortical carcinomas (Weiss score $\geq 3$ ). The lines correspond to the median value of expression. Results are presented in $\log 10$ scale and are expressed as fold-change. All differences were significant by the Mann-Whitney $U$ test.

analyzed 24 ACT (five adenomas, 18 adenocarcinomas, and one undetermined tumor) and seven non-neoplastic samples obtained by Wilms tumor surgery, no difference was observed in the genes analyzed in this study. The small number of cases analyzed by West et al. (15) and the different approaches used (RQ-PCR vs microarray) could be responsible for these differences. Despite the wide range of gene expression values, some of them such as CASP9, CASP 3, NFKB, TNF, and BCL2 showed a significant association with clinical and prognostic features.

CASP9 is an apoptosis-related cysteine protease that plays a central role in intrinsic and mitochondrial apoptosis pathways. Once activated, caspase 9 cleaves and activates the effector caspases 3 and 7 , which target key proteins for proteolysis to induce cell death (18). The association of higher CASP9 expression with a higher chance of unfavorable events in ACT detected in this study may be surprising. Very few reports on a prognostic influence of CASP9 expression in cancer have been published until now, with conflicting results. In large B-cell lymphomas, inhibition of CASP9 was strongly associated with a poor response to chemotherapy (19). However, as described here, other studies have 

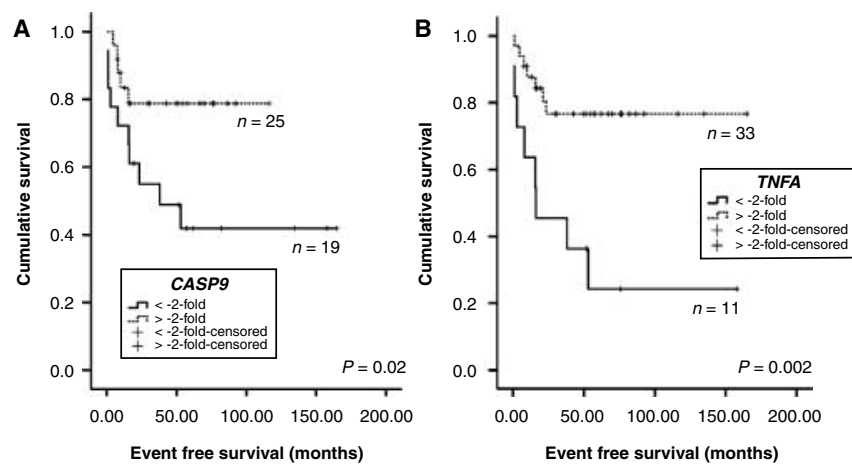

Figure 5 Kaplan-Meier plots of cumulative event-free survival (EFS) and cumulative incidence of events according to relative gene expression values below or twofold above the non-neoplastic adrenal samples for CASP3 (A) and TNF (B) in the group of ACT patients with adrenocortical carcinomas (Weiss score $\geq 3$ ).

associated higher expression levels of CASP9 with poor survival in colon carcinomas (20) and with the metastatic potential of non-small-cell lung cancer (21). The real significance of this association remains to be determined.

Lower expression of CASP 3 was observed in patients classified as stage IV and was also associated with a higher risk of unfavorable events (relapse/death) in patients with Weiss criteria $\geq 3$. In agreement with our findings, the association of lower levels of CASP 3 with a poor prognosis has been described in several human cancers including gastric carcinomas (22), ovarian carcinomas (23), hepatocellular carcinomas (24), childhood acute lymphoblastic leukemia (25), and esophageal cancer (26).

NFKB is a member of inflammation-related transcription factors that is activated in several human cancers and can promote or oppose tumor development. Its activation elevates the expression of several cell cycle, antiapoptotic, and inflammation-related genes, including BCL2 and TNF $(27,28)$. The activation of NFKB has been classically described as capable of inducing antiapoptotic proteins resulting in an increase in proliferation, inhibition of apoptosis, and stimulation of angiogenesis $(27,28,29)$. There is also strong evidence of inhibitory effects on tumor development in models of chemically induced skin and liver cancers (29, 30). This evidence that NFKB has an inhibitory effect on some kinds of cancers could explain its low expression levels in more advanced stages of childhood ACT as observed in this study.

TNF, a major inflammatory cytokine, is being reported to exert both positive and negative effects on human neoplasias (31). In this study, a lower level of mRNA expression of this gene was significantly associated with poor prognostic factors. Similar associations were also observed at the protein level when analyzed by IHC. In agreement with our results, in adrenocortical cell lines, TNF was able to regulate steroidogenesis, apoptosis, and cell viability $(32,33)$. In these cells, TNF increased apoptosis and consequently decreased cell viability (32). This property of apoptosis induction by TNF has also been observed in other human cancers (31).

The BCL2 gene codes an external mitochondrial membrane protein that acts as an antiapoptotic factor. In this study, lower levels of mRNA expression of this gene were significantly associated with poor prognostic factors. The same associations were also observed at the protein level when analyzed by IHC. Contradictory results about BCL2 expression have been described in cancer cell lines from different human tumors (34). In breast cancer patients, higher expression of BCL2 has been associated with a good prognosis (35). Similar results have also been reported for esophageal, cervical and head, and neck carcinomas and colorectal adenocarcinomas $(36,37,38)$. In Hodgkin's lymphoma, association of prostate carcinomas, testicular carcinomas, and acute myelogenous leukemia has been described to have opposite effects, with higher expression values being associated with a dismal prognosis $(39,40,41,42)$. The antiapoptotic role of BCL2 has been well characterized but the exact mechanism by which BCL2 might exert its protective effect on some kinds of cancers is still unclear. It has been suggested that in some cancers, the antiproliferative effect of BCL2 could translate into tumor suppression $(34,43)$. BCL2 expression prolongs G0, delaying G1 progression and G1-S transition and being able to inhibit cell growth (43). In colon cancer cell lines, BCL2 inhibited proliferation to the same extent as TP53 $(34,43)$. This cell growth inhibition by BCL2 was also observed in lung adenocarcinomas, glioblastoma cell lines, and multi-stage liver carcinogenesis models $(34,43)$. In this study, the mean BCL2 gene expression was significantly higher in patients with lower mitotic
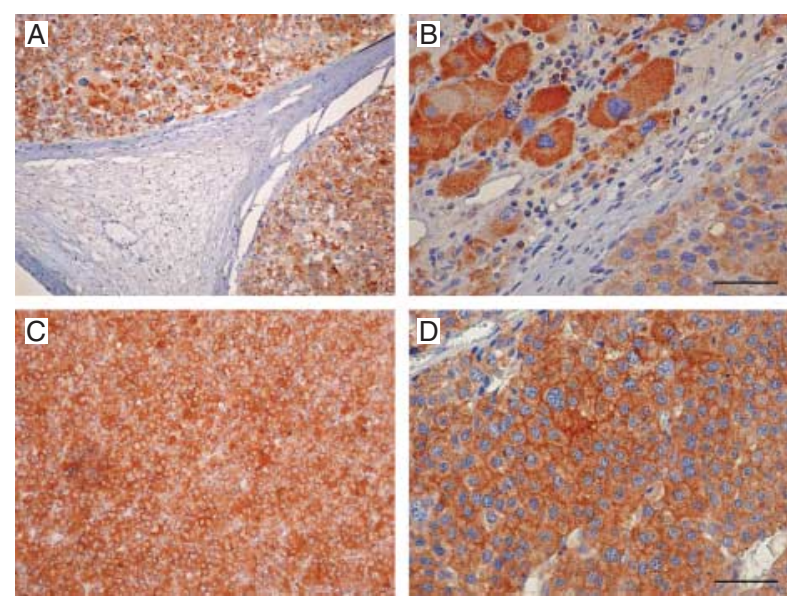

Figure $6 \mathrm{IHC}$ staining. A sample of adrenal tissue with cytoplasmic expression of $B C L 2$ ( $A$ and $B$ ) and $T N F(C$ and $D)$. Original magnification $\times 10(A$ and $C), \times 400(B$ and $D)$, scale bar $50 \mu \mathrm{m}$. 
index, reinforcing an antiproliferative effect of BCL2 in pediatric ACT.

Despite the wide range of expression values of the genes analyzed, the association of lower mRNA and protein expression values of BCL2 and TNF with classical unfavorable prognostic factors such as age, size, stage, and lower survival in both uni- and multivariate analyses suggests that these genes could be potential prognostic markers in childhood ACT.

Due to the high prevalence of the $p . R 337 \mathrm{H}$ mutation in this patient cohort, the results could not be generalizable to other pediatric ACT cohorts without this mutation. In this way, the prognostic significance of TNF and BCL2 expression must be viewed with caution, remaining somewhat a matter of discussion, and need to be validated in an independent cohort.

\section{Conclusion}

In conclusion, this study demonstrated for the first time abnormal expression of apoptosis-related genes in childhood ACT and its association with the biology and prognosis, suggesting a potential role of these genes in the pathogenesis of these tumors. The data presented here show that genes such as TNF and BCL2 have prognostic potential and might be used to improve stratification of childhood ACT.

\section{Supplementary data}

This is linked to the online version of the paper at http://dx.doi.org/10. 1530/EJE-12-0183.

\section{Declaration of interest}

The authors declare that there is no conflict of interest that could be perceived as prejudicing the impartiality of the research reported.

\section{Funding}

This collaborative study was supported by the Public Brazilian Research Agencies: Fundação de Amparo a Pesquisa do Estado de São Paulo (FAPESP), Conselho Nacional de Desenvolvimento Científico e Tecnológico (CNPq), and FAEPA (Brazil).

\section{References}

1 Michalkiewicz E, Sandrini R, Figueiredo B, Miranda ECM, Caran E, Oliveira-Filho AG, Marques E, Pianovski MAD, Lacerda L, Cristofani LM, Jenkins J, Rodriguez-Galindo C \& Ribeiro R. Clinical and outcome characteristics of children with adrenocortical tumors: a report from the International Pediatric Adrenocortical Tumor Registry. Journal of Clinical Oncology 200422 838-845. (doi:10.1200/JCO.2004.08.085)

2 Rodriguez-Galindo C, Figueiredo BC, Zambeti GP \& Ribeiro R. Biology, clinical characteristics, and management of adrenocortical tumors in children. Pediatric Blood E Cancer 200545 265-273. (doi:10.1002/pbc.20318)
3 Almeida $\mathrm{MQ}$ \& Latronico AC. The molecular pathogenesis of childhood adrenocortical tumors. Hormone and Metabolic Research 200739 461-466. (doi:10.1055/s-2007-981476)

4 Ribeiro RC, Michalkiewicz EL, Figueiredo BC, DeLacerda L, Sandrini F, Pianovsky MD, Sampaio G \& Sandrini R. Adrenocortical tumors in children. Brazilian Journal of Medical and Biological Research 200033 1225-1234. (doi:10.1590/S0100-879X 2000001000013)

5 Latronico AC, Pinto EM, Domenice S, Fragoso MC, Martin RM, Zerbini MC, Lucon AM \& Mendonca BB. An inherited mutation outside the highly conserved DNA-binding domain of the p53 tumor suppressor protein in children and adults with sporadic adrenocortical tumors. Journal of Clinical Endocrinology and Metabolism 200186 4970-4973. (doi:10.1210/jc.86.10.4970)

6 Sandrini F, Villani DP, Tucci S, Moreira AC, De Castro M \& Elias LLK. Inheritance of $\mathrm{R} 337 \mathrm{H} \mathrm{p} 53$ gene mutation in children with sporadic adrenocortical tumor. Hormone and Metabolic Research 200537 231-235. (doi:10.1055/s-2005-861373)

7 Spencer SJ, Mesiano S, Lee JY \& Jaffe RB. Proliferation and apoptosis in human adrenal cortex during fetal and perinatal periods: implications for growth and remodeling. Journal of Clinical Endocrinology and Metabolism $1999 \mathbf{8 4} 1110-1115$. (doi:10.1210/jc.84.3.1110)

8 Coulter CL. Fetal adrenal development: insight gained from adrenal tumors. Trends in Endocrinology and Metabolism 200516 235-242. (doi:10.1016/j.tem.2005.05.010)

9 El Wakil A, Doghman M, Latre De Late P, Zambetti GP, Figueiredo BC \& Lalli E. Genetics and genomics of childhood adrenocortical tumors. Molecular and Cellular Endocrinology 2011 336 169-173. (doi:10.1016/j.mce.2010.11.008)

10 Schteingart DE, Benitez R, Bradford C, Narayan A \& Wang S. Expression of anti-apoptosis genes determines the response of adrenal cancer to apoptosis-inducing chemotherapy. Anticancer Research 201030 4805-4809.

11 Sandrini R, Ribeiro RC \& DeLacerda L. Childhood adrenocortical tumors. Journal of Clinical Endocrinology and Metabolism $1997 \mathbf{8 2}$ 2027-2031. (doi:10.1210/jc.82.7.2027)

12 Weiss LM, Medeiros LJ \& Vickery AL. Pathologic features of prognostic significance in adrenocortical carcinoma. American Journal of Surgical Pathology 198913 202-206. (doi:10.1097/ 00000478-198903000-00004)

13 Livak KS \& Schmittgen TD. Analysis of relative gene expression data using real-time quantitative PCR and $2-\Delta \Delta C_{\mathrm{T}}$ method. Methods 200145 402-408. (doi:10.1006/meth.2001.1262)

14 Mesiano S \& Jaffe RB. Role of growth factors in the developmental regulation of the human fetal adrenal cortex. Steroids $1997 \mathbf{6 2}$ 62-72. (doi:10.1016/S0039-128X(96)00161-4)

15 West AN, Neale GA, Pounds S, Figueredo BC, RodriguezGallindo C, Pianovski MAD, Oliveira Filho AG, Malkin D, Lali E, Ribeiro R \& Zambetti GP. Gene expression profiling of childhood adrenocortical tumors. Cancer Research $2007 \quad 67$ 600-608. (doi:10.1158/0008-5472.CAN-06-3767)

16 Hanahan D \& Weinberg RA. The hallmarks of cancer. Cell 2000 100 57-70. (doi:10.1016/S0092-8674(00)81683-9)

17 Brown JM \& Attardi LD. The role of apoptosis in cancer development and treatment response. Nature Reviews. Cancer 20055 231-237. (doi:10.1038/nrc1560)

18 Allan LA \& Clarke PR. Apoptosis and autophagy: regulation of caspase-9 by phosphorylation. FEBS Journal $2009 \mathbf{2 7 6}$ 6063-6073. (doi:10.1111/j.1742-4658.2009.07330.x)

19 Muris JJ, Cillessen SA, Vos W, van Houdt IS, Kummer JA, van Krieken JH, Jiwa NM, Jansen PM, Kluin-Nelemans HC, Ossenkoppele GJ, Gundy C, Meijer CJ \& Oudejans JJ. Immunohistochemical profiling of caspase signaling pathways predicts clinical response to chemotherapy in primary nodal diffuse large B-cell lymphomas. Blood 2005105 2916-2923. (doi:10.1182/ blood-2004-07-2716)

20 Sträter J, Herter I, Merkel G, Hinz U, Weitz J \& Möller P. Expression and prognostic significance of APAF-1, caspase- 8 and caspase-9 in 
stage II/III colon carcinoma: caspase- 8 and caspase- 9 is associated with poor prognosis. International Journal of Cancer $2010 \mathbf{1 2 7}$ 873-880. (doi:10.1002/ijc.25111)

21 Papay J, Krenacs T, Moldvay J, Stelkovics E, Furak J, Molnar B \& Kopper L. Immunophenotypic profiling of nonsmall cell lung cancer progression using the tissue microarray approach. Applied Immunohistochemistry \& Molecular Morphology 200715 19-30. (doi:10.1097/01.pai.0000213143.32030.f5)

22 Kim MA, Lee HE, Lee HS, Yang HK \& Kim WH. Expression of apoptosis-related proteins and its clinical implication in surgically resected gastric carcinoma. Virchows Archiv 2011459 503-510. (doi:10.1007/s00428-011-1150-6)

23 Espinosa I, Catasus L, Canet B, D’Angelo E, Muñoz J \& Prat J. Gene expression analysis identifies two groups of ovarian high-grade serous carcinomas with different prognosis. Modern Pathology 201124 846-854. (doi:10.1038/modpathol.2011.12)

24 Huang H, Zhang XF, Zhou HJ, Xue YH, Dong QZ, Ye QH \& Qin LX. Expression and prognostic significance of osteopontin and caspase-3 in hepatocellular carcinoma patients after curative resection. Cancer Science 2010101 1314-1319. (doi:10.1111/j. 1349-7006.2010.01524.x)

25 Mata JF, Silveira VS, Mateo EC, Cortez MA, Queiroz RG, Yunes JA, Lee ML, Toledo SR, Petrilli AS, Brandalise SR, Tone LG \& Scrideli CA. Low mRNA expression of the apoptosis-related genes CASP3, CASP8, and FAS is associated with low induction treatment response in childhood acute lymphoblastic leukemia (ALL). Pediatric Blood \& Cancer 201055 100-107. (doi:10.1002/ pbc.22463)

26 Jiang H, Gong M, Cui Y, Ma K, Chang D \& Wang TY. Upregulation of caspase-3 expression in esophageal cancer correlates with favorable prognosis: an immunohistochemical study from a high incidence area in northern China. Diseases of the Esophagus 2010 23 487-492. (doi:10.1111/j.1442-2050.2009.01043.x)

27 Karin M, Cao Y, Greten FR \& Li ZW. NF-kappaB in cancer: from innocent bystander to major culprit. Nature Reviews. Cancer 2002 2 301-310. (doi:10.1038/nrc780)

28 Karin M. Nuclear factor-kappaB in cancer development and progression. Nature $2006 \quad \mathbf{4 4 1} 431-436 . \quad$ (doi:10.1038/ nature04870)

29 Watson C, Miller DA, Chin-Sinex H, Losch A, Hughes W, Sweeney C \& Mendonça MS. Suppression of NF- $\kappa$ B activity by parthenolide induces X-ray sensitivity through inhibition of splitdose repair in TP53 null prostate cancer cells. Radiation Research 2009171 389-396. (doi:10.1667/RR1394.1)

30 van Hogerlinden G, Auer R \& Toftgård R. Inhibition of Rel/nuclear factor-kappaB signaling in skin results in defective DNA damageinduced cell cycle arrest and Ha-ras- and p53-independent tumor development. Oncogene 200221 4969-4977. (doi:10.1038/sj. onc. 1205620)

31 Balkwill F. Tumour necrosis factor and cancer. Nature Reviews. Cancer 20099 361-371. (doi:10.1038/nrc2628)

32 Mihhaylova IV, Kuulasmaa T, Jääskeläinen J \& Voutilainen R. Tumor necrosis factor- $\alpha$ regulates steroidogenesis, apoptosis, and cell viability in human adrenocortical cell line NCI-H295R. Endocrinology 2007148 386-392. (doi:10.1210/en.2006-0726)

33 Judd AM, Call GB, Barney M, McIlmoil CJ, Balls AG, Adams A \& Oliveira GK. Possible function of IL-6 and TNF as intraadrenal factors in the regulation of adrenal steroid secretion. Annals of the New York Academy of Sciences 2000917 628-637. (doi:10.1111/j. 1749-6632.2000.tb05428.x)

34 Pietenpol JA, Papadopoulos N, Markowitz S, Willson JK, Kinzler KW \& Vogelstein B. Paradoxical inhibition of solid tumor cell growth by bcl2. Cancer Research $1994 \mathbf{5 4} 3714-3717$.

35 Callagy GM, Weber MJ, Pharoah PD \& Caldas C. Meta-analysis confirms BCL2 is an independent prognostic marker in breast cancer. BMC Cancer 20088 1-10. (doi:10.1186/1471-24078-153)

36 Ohbu M, Saegusa M, Kobayashi N, Tsukamoto H, Mieno H, Kakita A \& Okayasu I. Expression of bcl-2 protein in esophageal squamous cell carcinomas and its association with lymph node metastasis. Cancer $1997 \quad 79$ 1287-1293. (doi:10.1002/ (SICI)1097-0142(19970401)79:7 < 1287::AID-CNCR3 > 3.0. $\mathrm{CO} ; 2-\mathrm{E})$

37 Buglioni S, D’Agnano I, Cosimelli M, Vasselli S, D'Angelo C. Tedesco M, Zupi G \& Mottolese M. Evaluation of multiple biopathological factors in colorectal adenocarcinomas: independent prognostic role of p53 and bcl-2. International Journal of Cancer 199984 545-552. (doi:10.1002/(SICI)1097-0215(19991222) $84: 6<545::$ AID-IJC1 > 3.0.CO;2-2)

38 Dimitrakakis C, Kymionis G, Diakomanolis E, Papaspyrou I, Rodolakis A, Arzimanoglou I, Leandros E \& Michalas S. The possible role of p53 and bcl-2 expression in cervical carcinomas and their premalignant lesions. Gynecologic Oncology 200077 129-136. (doi:10.1006/gyno.1999.5715)

39 Eid H, Gulyas M, Geczi L, Bodrogi I, Institiris E \& Bak M. Expression of bcl-2 in testicular carcinoma: correlation with tumor progression and MDR1/Pgp. Cancer 1998 83 331-336. (doi:10. 1002/(SICI)1097-0142(19980715)83:2 < 331::AID-CNCR17> 3.0.CO;2-U)

40 Keshgegian AA, Johnston E \& Cnaan A. Bcl-2 oncoprotein positivity and high MIB-1 (Ki-67) proliferative rate are independent predictive markers for recurrence in prostate carcinoma. American Journal of Clinical Pathology $1998110443-449$.

41 Garcia JF, Camacho FI, Morente M, Faga M, Montalbán C, Alvaro T, Bellas C, Castaño A, Diez A, Flores T, Martín C, Martinez MA, Mazorra F, Menargues J, Mestre MJ, Molejo M, Saez AI, Sámchez L \& Piris MA. Hodgkin and Reed-Sternberg cells harbor alterations in the major tumor suppressor pathways and cell-cycle checkpoints: analyses using tissue microarrays. Blood 2003101 681-689. (doi:10.1182/blood-2002-04-1128)

42 Thomadaki H \& Scorilas A. BCL2 family of apoptosis-related genes: functions and clinical implications in cancer. Critical Reviews in Clinical Laboratory Sciences 200643 1-67. (doi:10.1080/ 10408360500295626 )

43 Zinkel S, Gross A \& Yang E. BCL2 family in DNA damage and cell cycle control. Cell Death and Differentiation 200613 1351-1359. (doi:10.1038/sj.cdd.4401987)

Received 2 March 2012

Revised version received 16 May 2012

Accepted 22 May 2012 